\title{
Preface to Special Issue on 5th UK Catalysis Conference (UKCC 2019)
}

\author{
Simon Kondrat ${ }^{1} \cdot$ Christopher Hardacre $^{2} \cdot$ Christopher Parlett $^{3}$
}

Published online: 17 July 2020

(c) Springer Science+Business Media, LLC, part of Springer Nature 2020

Within this special issue of Topics in Catalysis, we present a range of articles submitted in association with the 5th UK Catalysis Conference held in Loughborough from the 9th-11th of January 2019. The conference, once again, saw strong engagement from across the UK and international catalysis community. Recent advances and new concepts from across this rich multidisciplinary scientific field were discussed with infectious purpose in the short, but bright days of the new year. The breadth of catalysis discussed, from biocatalysts, through to heterogeneous and homogeneous catalytic chemistry and chemical engineering, ensuring that the conference was a highlight of the UK catalysis conference calendar. In bringing the community together the conference realises one of the roles of the UK Catalysis Hub, whose ambition is to retain and strengthen the UK's research excellence in the field of catalysis.

The 5th UK Catalysis Conference coincided with the second phase of the UK Catalysis Hub, with a reinvigorated focus on supporting core aspects of interaction within the community. The conference also reflected the emergent research themes within the hub of; (1) Optimising, predicting and designing new catalysts, (2) Catalysis at the water-energy nexus and (3) Catalysis for the circular economy.

In this regard we received outstanding contributions from subjects including, emission control catalysis, biogas and syngas chemistry, mathematical modelling of kinetics and advanced catalyst characterisation. All contributions were highly topical, offering contributions of new results and scientific ideas. Also, several articles we noted to be from early career researchers, showing that the community and catalysis research has a bright future.

Writing this during the disruption and isolation of the recent COVID-19 pandemic, the role of organisations like the UK Catalysis Hub and our European/international counterparts in bringing our scientific community together, is manifestly more important than ever before. We look forward to meeting again at a future UK Catalysis Conference.

Publisher's Note Springer Nature remains neutral with regard to jurisdictional claims in published maps and institutional affiliations.
Simon Kondrat

s.kondrat@lboro.a.uk

1 Department of Chemistry, Loughborough University, Epinal Way, Loughborough, Leicestershire LE11 3TU, UK

2 School of Chemical Engineering \& Analytical Science, The University of Manchester, The Mill, Sackville Street Campus, Manchester M13 9PL, UK

3 The University of Manchester at Harwell, Diamond Light Source, Harwell Campus, Didcot, Oxfordshire OX11 0DE, UK 